\title{
Performance Characteristics of a Cooking Stove Improved with Sawdust as an Insulation Material
}

\author{
Jasper Okino $\mathbb{D}^{1,2,3}$ Allan John Komakech ${ }^{10},{ }^{1}$ Joshua Wanyama, ${ }^{1}$ Herbert Ssegane $\mathbb{D},{ }^{1}$ \\ Elly Olomo $\mathbb{D}^{2,3}$ and Timothy Omara $\mathbb{D D}^{3,4,5}$ \\ ${ }^{1}$ Department of Agricultural and Bio-systems Engineering, School of Food Technology, Nutrition and Bio-Engineering, \\ College of Agricultural \& Environmental Sciences (CAES), Makerere University, P.O. Box 7062, Kampala, Uganda \\ ${ }^{2}$ Department of Mechanical, Production and Energy Engineering, School of Engineering, Moi University, Uasin Gishu County, \\ P.O. Box 3900, Eldoret, Kenya \\ ${ }^{3}$ Africa Center of Excellence II in Phytochemicals, Textile and Renewable Energy (ACE II PTRE), Moi University, \\ Uasin Gishu County, P.O. Box 3900, Eldoret, Kenya \\ ${ }^{4}$ Department of Chemistry and Biochemistry, School of Sciences and Aerospace Studies, Moi University, Uasin Gishu County, \\ P.O. Box 3900, Eldoret, Kenya \\ ${ }^{5}$ Department of Quality Control and Quality Assurance, AgroWays Uganda Limited, Plot 34-60, Kyabazinga Way, \\ P.O. Box 1924, Jinja, Uganda
}

Correspondence should be addressed to Jasper Okino; okinojasper@gmail.com

Received 6 March 2021; Revised 28 April 2021; Accepted 20 May 2021; Published 29 May 2021

Academic Editor: Pallav Purohit

Copyright $\odot 2021$ Jasper Okino et al. This is an open access article distributed under the Creative Commons Attribution License, which permits unrestricted use, distribution, and reproduction in any medium, provided the original work is properly cited.

In developing countries, energy demand from biomass has increased due to exponential population growth. This has translated into voluminous quantities of wood being used. The situation is exacerbated by the popular use of inefficient stoves with low thermal insulation, hence contributing to deforestation. In this study, the performance of a cooking stove improved with sawdust as an insulation material was assessed. An insulated fire stove prototype of $26 \mathrm{~cm}$ saucepan diameter was designed, constructed, and cast with sawdust and clay in a ratio of $1: 1$ (as the first layer) and sawdust alone as the second layer. The developed stove was tested using a water boiling test to establish its operating performance. The thermal efficiency of the stove was assessed using indigenous wood fuels used in rural Uganda (Senna spectabilis, Pinus caribaea, and Eucalyptus grandis). Computational fluid dynamics was used to simulate the temperature and velocity fields within the combustion chamber and for generating temperature contours of the stove. Obtained results indicated that $S$. spectabilis had the highest thermal efficiency of $35.5 \pm 2.5 \%$, followed by E. grandis $(25.7 \pm 1.7 \%)$ and lastly $P$. caribaea $(19.0 \pm 1.2 \%)$ in the cold start phase when compared with traditional stoves. The stove remained cold as hot air was restricted to the combustion chamber with decreasing temperature contours toward the outer wall up to the ambient temperature. The velocity flow remained constant as the chamber was colored green throughout due to the shielding of the stove with sawdust as insulation. The heat flux generated indicated that a thick layer of $6 \mathrm{~cm}$ or more could ensure good insulation, and this could be further reduced by introducing more sawdust. The designed stove has the potential to reduce biomass consumption and emissions when compared to traditional cookstoves. The inclusion of a chimney draught in the fire stove prototype could reduce smoke and increase thermal efficiency. Further studies should focus on minimizing the thickness of the clay-sawdust (first) layer and increasing the thickness of the sawdust layer to reduce the weight of the fire stove.

\section{Introduction}

At least $50 \%$ of people in developing countries still cook and heat their homes using solid fuels (i.e., wood fuel, crop residues, charcoal, and animal dung) in open fires and leaky stoves [1-4]. Using open fires in household cooking consumes more energy than any other end-use services in developing countries [5]. Such inefficient cooking technologies are also associated with high levels of household air pollution with a range of toxic pollutants as well as irrational 
consumption of biomass fuels [6, 7]. Biomass is reported to be the world's fourth largest energy source for cooking $[8,9]$. Harmful emissions from traditional biomass cookstoves attributed nearly 3.8 million deaths per year globally $[10,11]$. In Africa, and Sub-Saharan Africa specifically, at least 753 million people (i.e., $80 \%$ of the population) use biomass as an energy source [12]. Uganda is one of the developing countries in Sub-Sahara where more than $90 \%$ of the country's population relies on biomass feedstocks [13-15]. The feedstocks are usually consumed with the use of traditional open fire (three-stone) stoves that have comparatively lower efficiency (about 15.6\%) and higher fuel consumption $[16,17]$ when compared to improved biomass cookstoves [18]. This has led to natural forest degradation as well as a shortage of wood fuel for cooking in some parts of Uganda [13].

The performance (thermal efficiency) and the attendant emissions from biomass cookstoves are dictated by various factors such as the stove type (design), fuel feeding practice, lighting, and combustion temperature [9, 19]. Sustainable biomass fuel utilization and improvement of thermal efficiency of cookstoves can be achieved through the use of good insulating materials, clean fuel(s), or adopting unique designs that facilitate fuel combustion [7, 19]. For instance, Darlami et al. [20] reported that the thermal efficiency of a traditional Nepalese cookstove increased by $7.60 \%$ (from $18 \%$ to $25.6 \%$ ) when it was modified with mud. The authors argued that the improvement could accrue logistic advantages to Nepalese households. Similarly, Oyejide et al. [19] adaptively designed a modular stove utilizing briquettes from a pleustophytic invasive weed (water hyacinth). The stove reportedly had an average thermal efficiency of $70.51 \%$, which is more efficient than most popular traditional stoves currently in use. In a recent study, Perez et al. [21] designed a $3 \mathrm{~kW}$ stove based on biomass gasification, together with an agricultural waste-derived fuel as an alternative to charcoal. It was found that using the improved cookstove reduced charcoal consumption by $61 \%$ vis-à-vis traditional cookstoves. Comparable fuel savings were reported for the cookstove when biomass solid waste fuels were used. Interestingly, the biomass solid waste fuels afforded carbon monoxide emission reduction of $41 \%$ and $67 \%$ and fine particulate matter of $84 \%$ and $93 \%$ during the high and low power phases of the tests, respectively. The estimated savings from the use of the designed stove along with the biomass solid waste fuels and charcoal included an $18 \%$ reduction in the cooking time, savings of $\$ 353.5$ per year per family in the purchase of fuel, and an emission reduction of 3.2 tonnes of carbon dioxide per year per family [21]. Recently, Shanono et al. [7] demonstrated the feasibility of using Jatropha Oil Bio Stove and Neem Oil Bio Stove utilized blends of raw oils of Jatropha and Neem with Kerosene as biofuels. From an environmental standpoint, the stoves were reported to reduce the amount of harmful emissions when the fuel used was a blend of kerosene and vegetable oils [7].

It is established that incorporation of an insulation layer in the combustion chamber of cookstoves minimizes heat transfer to the walls which ultimately results in high combustion chamber temperature, enhanced combustion efficiency, and ultimately thermal efficiency [20]. Sawdust is one of the biomass solid waste fuels and insulating materials which can be used to increase the thermal efficiency of cookstoves [20, 22-25]. This waste is mainly generated from sawmills, carpentry workshops, and pit sawing. In most instances, sawdust is not utilized and is just dumped. This creates disposal problems [26], and in some instances, sawdust is burnt which results in environmental pollution [27]; i.e., burning produces smoke and gases such as carbon dioxide and carbon monoxide, which are hazardous to human health and also contribute to the greenhouse gases pool in the atmosphere.

From the retrieved literature, there is a paucity of published information on cookstoves improved with sawdust as an insulation material. Further, no studies have assessed such a stove with performance optimization. This study, therefore, aimed at assessing the performance characteristics of a cooking stove improved with sawdust as an insulation material. Given the nature of sawdust, a binding agent is usually required when it is used [28]. Therefore, sawdust mixed with clay (as a binding agent) was used in this study as the first insulation layer.

\section{Materials and Methods}

\subsection{Stove Sizing and Construction}

2.1.1. Stove Sizing Considerations. The size of the saucepan determines the dimensions of a cookstove. A $26 \mathrm{~cm}$ aluminum saucepan diameter with $1.2 \mathrm{~mm}$ thickness was selected for sizing the fire stove prototype as commonly used by typical households in Uganda. Cast iron and mild steel were selected as essential metal sheets for fabricating the stove components. The former was selected due to its resistance to heat and ability to dissipate heat quickly. A cast iron plate with $1.2 \mathrm{~mm}$ thickness was used to construct the combustion chamber, fire magazine, air magazine, and saucepan skirt. A mild steel plate $(1.2 \mathrm{~mm})$ was used to construct the bottom plate, top plate, and inner and outer cylinders of the stove. Hard steel was used to construct the grate due to its heat-resistant nature. The relationship between the saucepan (pot) diameter and the combustion chamber was taken into consideration during the sizing of the stove (Table 1; Figure 1). Sawdust and clay were selected as the casting materials.

2.1.2. Stove Dimensions. Isometric drawing of the different fire stove components was performed using CATIA software (p3 V5-6 R2016 SP4.0, Dessaut Systems, France) based on a $26 \mathrm{~cm}$ diameter saucepan (Figures 2 and 3 ).

2.1.3. Stove Construction. Two pieces of L-shaped cast iron plates $(130 \mathrm{~mm} \times 130 \mathrm{~mm})$ were welded to form a hollow square of $325 \mathrm{~mm}$ height for the combustion chamber. The other two pieces of L-shaped cast iron plates $(130 \mathrm{~mm} \times 90 \mathrm{~mm})$ were welded to form a hollow square of length $195 \mathrm{~mm}$ for the fire magazine. Another pair of L-shaped cast iron plates $(130 \mathrm{~mm} \times 40 \mathrm{~mm})$ were joined and 
TABLE 1: Relationship between saucepan/pot diameter and combustion chamber.

\begin{tabular}{lcccccc}
\hline Pot diameter, $D(\mathrm{~cm})$ & Pot capacity $(\mathrm{L})$ & $J(\mathrm{~cm})$ & $K=1.5 J(\mathrm{~cm})$ & $H=K+J(\mathrm{~cm})$ & Chamber area $\left(\mathrm{cm}^{2}\right)$ & Chamber sizing $^{2}$ \\
\hline Up to 20 & Up to 2.7 & 11 & 16.5 & 27.5 & 121 & $11 \times 11$ \\
$21-25$ & $2.7-7.5$ & 12 & 18.0 & 30.0 & 144 & $12 \times 12$ \\
$26-30$ & $7.5-9.8$ & 13 & 19.5 & 32.5 & 169 & $13 \times 13$ \\
$31-35$ & $9.8-15.7$ & 14 & 21.0 & 35.0 & 196 & $14 \times 14$ \\
\hline
\end{tabular}

$J=$ combustion chamber width, $K=$ combustion chamber height from fire magazine, $H=$ overall combustion chamber height, $D=$ saucepan diameter. Source: Ministry of Energy and Mineral Development [18, 29].

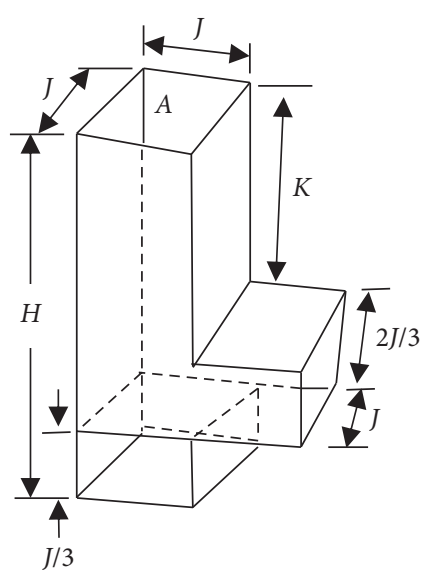

(a)

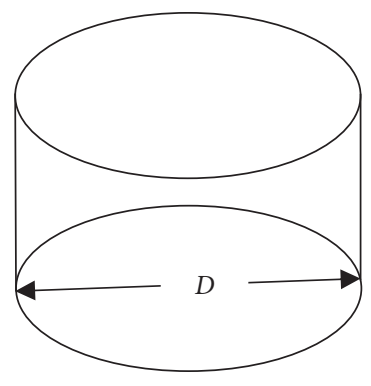

(b)

FIGURE 1: Relationship between saucepan/pot diameter and combustion chamber: (a) combustion chamber and (b) saucepan [18, 29].

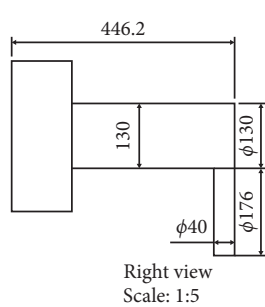

Scale: 1:5

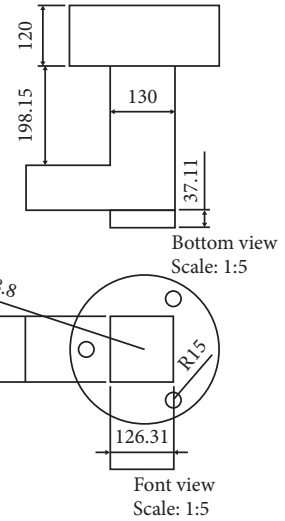

(a)

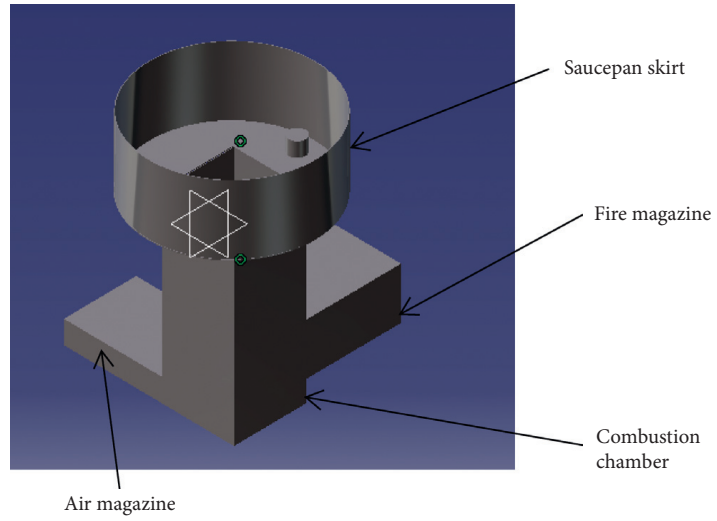

(b)

FIgURE 2: Combustion chamber, fire magazine, and air passage of the proposed stove: (a) drawing (dimensions) and (b) artistic impression.

welded from a hollow square of length $195 \mathrm{~mm}$ (air passage). The combustion chamber, fire magazine, and air passage were then joined and welded (Figure 4(a)).

The inner liner base was fabricated using a $300 \mathrm{~mm}$ diameter cast iron plate. A $130 \mathrm{~mm} \times 130 \mathrm{~mm}$ hollow square was then cut from the $300 \mathrm{~mm}$ diameter plate measured directly from the center of the plate to form an inner liner base. This was then welded on top of the combustion chamber. The saucepan skirt was fabricated using a $942 \mathrm{~mm} \times 120 \mathrm{~mm} \times 1.2 \mathrm{~mm}$ cast iron metal sheet. The $942 \mathrm{~mm}$ portion was bent to form a hollow section of $300 \mathrm{~mm}$ diameter with $120 \mathrm{~mm}$ height and $1.2 \mathrm{~mm}$ thickness. The hollow cylinder (saucepan skirt) was placed onto the inner liner base and the adjoining part was welded.

The inner cylinder was obtained by measuring and cutting out a $1256 \mathrm{~mm} \times 485 \mathrm{~mm}$ mild steel plate of thickness of $1.2 \mathrm{~mm}$. The obtained sheet plate was then bent to form a $400 \mathrm{~mm}$ diameter hollow cylinder for an inner cylinder with $485 \mathrm{~mm}$ height. The inner cylinder was then inserted and positioned concentrically with the inner liner, such that it was $50 \mathrm{~mm}$ from the inner liner walls. The outer cylinder was obtained by measuring and cutting out a $1570 \mathrm{~mm} \times 485 \mathrm{~mm}$ mild steel sheet of a thickness of $1.2 \mathrm{~mm}$. The cut sheet plate was bent to form a $500 \mathrm{~mm}$ diameter 


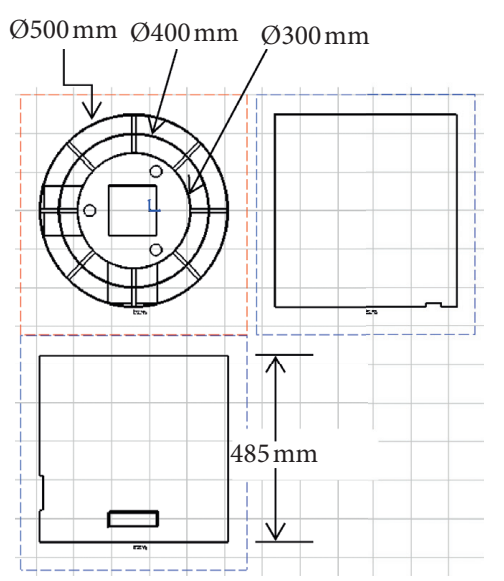

(a)

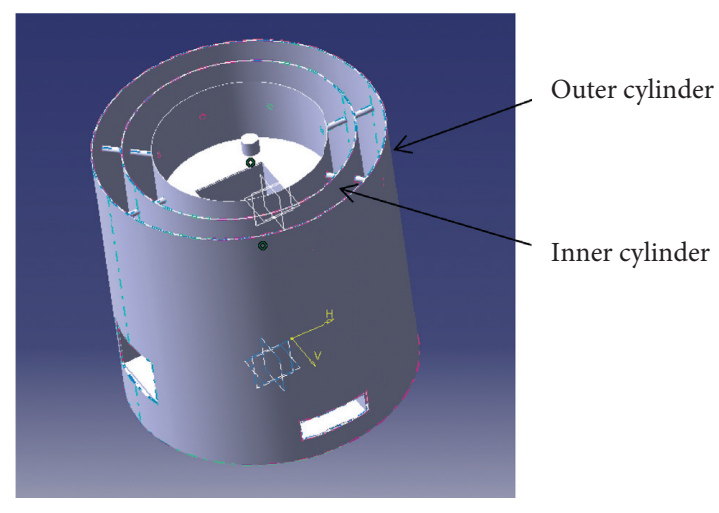

(b)

Figure 3: Components of the proposed stove: (a) drawing (dimensions) and (b) artistic impression.

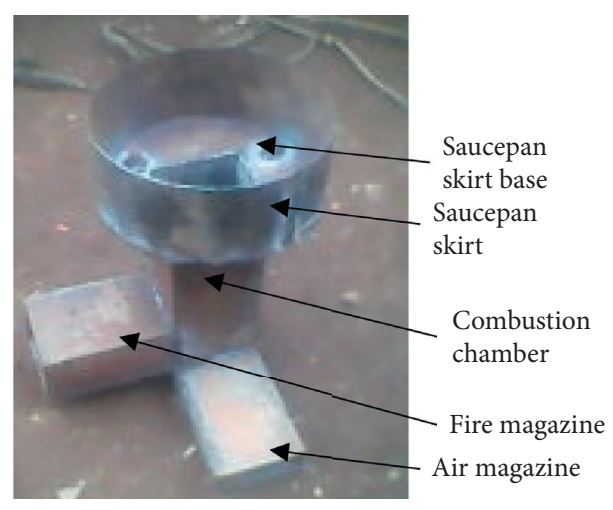

(a)

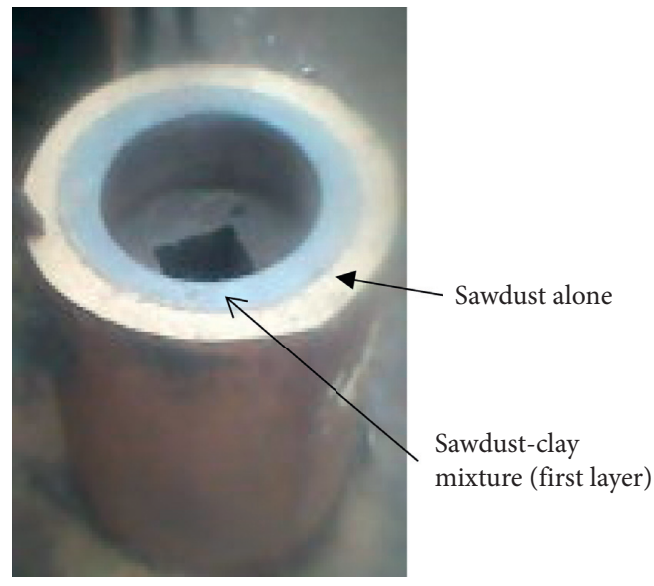

(c)

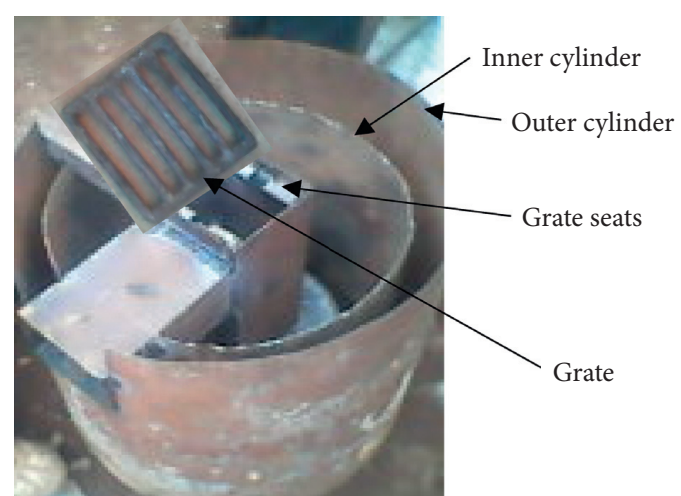

(b)

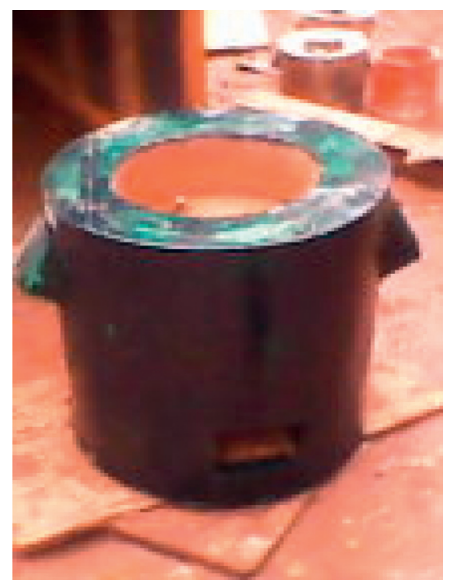

(d)

Figure 4: Pictorial synopsis of stove construction: (a) welded key parts, (b) grate and grate seats, (c) casting of the stove with insulations, and (d) painted stove.

hollow cylinder (the outer cylinder). This was inserted and positioned concentrically with the inner cylinder, such that it was $50 \mathrm{~mm}$ from the inner cylinder walls (Figure 4(b)).

The grate was made from $10 \mathrm{~mm}$ diameter hard steel. It was fabricated in a square form $(120 \mathrm{~mm} \times 120 \mathrm{~mm})$ so as to fit the hollow section of the combustion chamber
(Figure 4(b)). Six pieces of hard steel of length $100 \mathrm{~mm}$ spaced at $12 \mathrm{~mm}$ and two pieces of hard steel (length $120 \mathrm{~mm}$ and diameter $10 \mathrm{~mm}$ each) were cut, joined, and then welded to form a square of size $120 \mathrm{~mm} \times 120 \mathrm{~mm}$.

The bottom plate $(500 \mathrm{~mm}$ in diameter) was made out of a $1.2 \mathrm{~mm}$ thick mild steel sheet and welded onto the bottom 
of the outer cylinder. The top plate $(500 \mathrm{~mm}$ in diameter) made of a $1.2 \mathrm{~mm}$ thick mild steel sheet was cut. A $300 \mathrm{~mm}$ diameter hollow circular section was cut from it to form a hollow circular plate. Clay and sawdust were sieved using a $2 \mathrm{~mm}$ wire mesh to ensure homogeneity of the mixture. Water was slowly added to the mixture of sawdust and clay $(1: 1)$ until when it was mouldable. The fire stove was then cast using the mouldable clay-sawdust mixture before being compressed to ensure uniform compaction (first layer). Sawdust alone was thereafter cast onto the stove in the remaining cylindrical space (second layer) as shown in Figure 4(c). This was compressed with a heavy solid material manually to ensure a uniform compaction rate. The fire stove was then painted green (Figure 4(d)).

\subsection{Computational Fluid Dynamics Simulation}

2.2.1. Stove Model Assumptions. The major assumption employed in the generation of a simple computational fluid dynamics (CFD) model of the fire stove was the replacement of the combustion process by a hot air stream using the CAD package as shown in Figure 5. In addition, the geometry of the fire stove prototype was simplified in a form usable by the computer.

2.2.2. Stove Model Boundary Conditions. The boundary conditions for the CFD model were defined as in Table 2. The thermal conductivity of clay, sawdust, and sawdust in clay used was as reported by Folaranmi [30].

2.2.3. Meshing and Simulation. The above assumptions and boundary conditions were used to simulate the stove using Ubuntu version 15.10 which is a Linux distribution. Ubuntu provides a platform for operating Salome ${ }^{\circledR}$ (version 7.7.1), CFMesh $^{\circledR}$ (version 1.1.1), OpenFoam ${ }^{\circledR}$ (version 3.0), and ParaView ${ }^{\circledR}$ (version 4.4.0) software. The surface mesh of the fire stove was generated using Salome ${ }^{\circledR}$ as shown in Figure 5. This was used for initiating the mesh in order to make small triangles to allow the computer to analyze the result in a more precise way. The surface mesh was then exported, and the volume mesh was generated using a script-based CFMesh $^{\circledR}$. The case was set up and solved in script-based OpenFoam. This was then postprocessed in ParaView* (version 4.4.0) which is a graphical user interface.

The BuoyantSimpleFoam which is an OpenFoam ${ }^{\circledR}$ solver was used. The energy source was provided with values such that the temperature is around $900 \mathrm{~K}$ (value taken from literature for wood combustion) as shown in Figure 5. The temperature and velocity were run at intervals of 0.5 seconds using Linux Ubuntu 15.10 until it stopped, and their profiles were generated in $\mathrm{ParaView}^{\circledR}$.

2.3. Testing Procedures. Stove testing was carried out at Biomass Energy Resource and Training Centre, Nyabyeya Forestry College on the fringes of Budongo forest, Masindi, Uganda. This place was chosen because of the availability of stove testing equipment and the selected tree species in the area.

2.3.1. Moisture Content of the Biomass Fuels. Senna spectabilis (Cassia species), Eucalyptus grandis (Eucalyptus species), and Pinus caribaea (pine species) as commonly used wood fuels in Uganda were employed in this study $[31,32]$. The first two were selected due to their high degree of coppicing while P. caribaea was selected because of its high resin content. Three replicates from the three biomass fuels were chopped into pieces $(2 \mathrm{~cm} \times 2 \mathrm{~cm} \times 2 \mathrm{~cm})$ using a petrol-powered re-saw machine. They were weighed using a calibrated Mettler PM200 digital analytical balance (Marshall Scientific, Hampton, NH, USA). The samples were put in an electric oven at $105^{\circ} \mathrm{C}$ for 24 hours and then reweighed. The moisture content of the biomass fuels was determined on both wet and dry basis (equations (1) and (2)) [33].

$$
\begin{aligned}
\mathrm{MC}_{\mathrm{wb}} & =\frac{\mathrm{MC}_{\mathrm{db}}}{1+\mathrm{MC}_{\mathrm{db}}} \times 100, \\
\mathrm{MC}_{\mathrm{db}} & =\frac{M_{i}-M_{f}}{M_{f}} \times 100,
\end{aligned}
$$

where $\mathrm{MC}_{\mathrm{db}}$ is the moisture content on a dry basis (\%), $\mathrm{MC}_{\mathrm{wb}}$ is the moisture content wet basis (\%), $M_{i}$ is the initial weight of fuel $(g)$, and $M_{f}$ is the final weight of fuel $(g)$.

2.3.2. Determination of Calorific Values of the Biomass Fuels. A copper bomb calorimeter was used to determine the calorific value of the biomass fuels used. A known mass of the fuel was fed into the calorimeter and lit to heat $2 \mathrm{~kg}$ of water. The fuel was burnt in the presence of oxygen until it was completely burnt. The change in temperature of the water was read from a handheld thermometer and recorded. The calorific value of the fuel was calculated using equation (3). Three replications were carried out for each biomass fuel, and the average calorific value was used in the determination of thermal efficiency.

$$
C=\frac{M_{w} C_{w}\left(T_{f}-T_{i}\right)+M_{c} C_{c}\left(T_{f}-T_{i}\right)}{M_{f}},
$$

$M_{w}$ is the mass of water used $(\mathrm{kg}), C_{\mathrm{w}}$ is the specific heat capacity of water $\left(4186.0 \mathrm{~kJ} \mathrm{~kg}^{-1} \mathrm{C}^{-1}\right)$, and $C_{\mathrm{c}}$ is the specific heat capacity of the calorimeter $\left(363.8 \mathrm{~kJ} \mathrm{~kg}^{-1} \mathrm{C}^{-1}\right)$.

2.3.3. Water Boiling Test. The water boiling test (WBT) was used to evaluate the overall thermal performance of the stove. This was achieved through three phases which consisted of (1) bringing water to a boil from a cold start, (2) bringing water to a boil when the stove is hot, and (3) maintaining the water at simmering temperatures. In the WBT experiment, water was heated to boiling point. The time taken to boil a given quantity of water, specific firewood consumption besides evaluating thermal efficiency at both high and low energy input was measured. The test was 


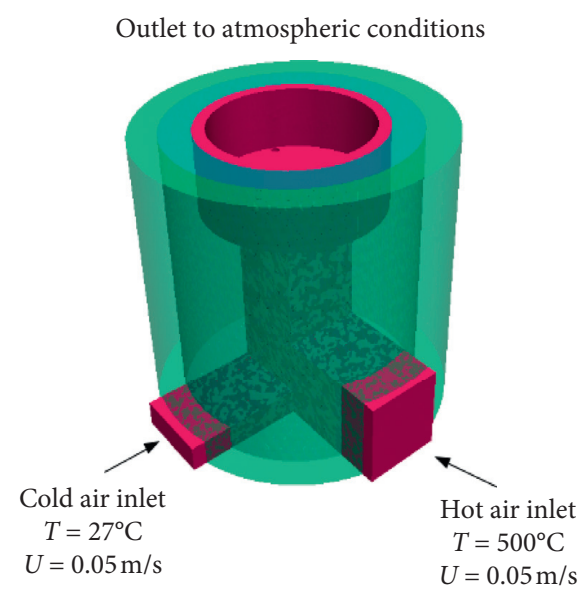

(a)

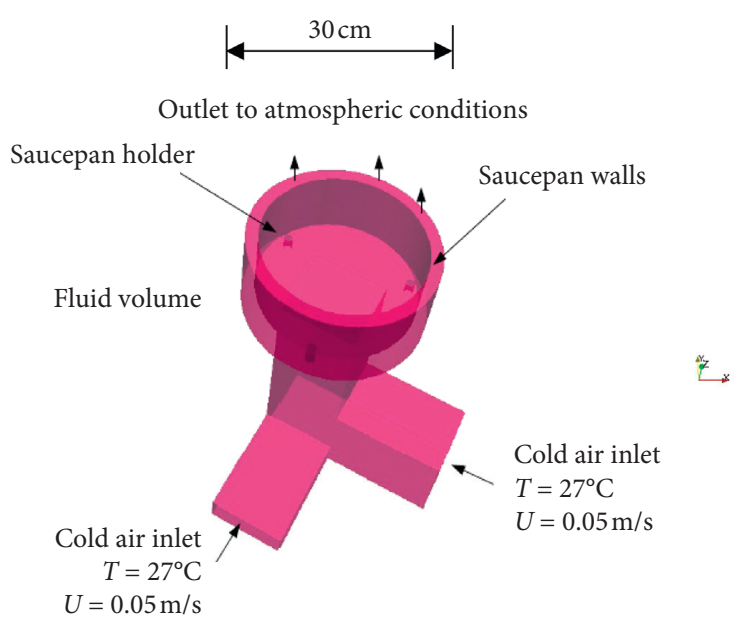

(b)

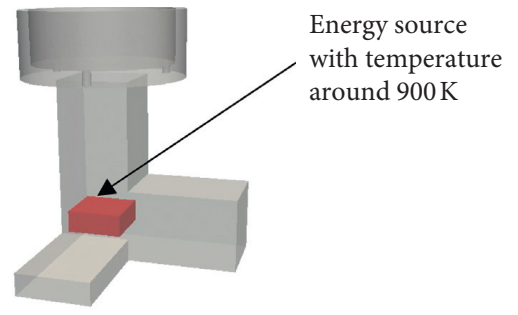

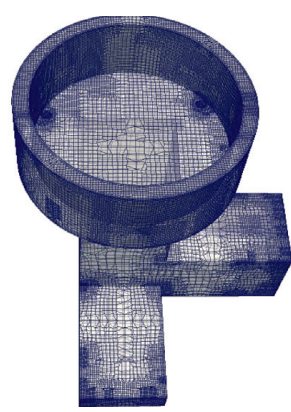

(d)

Figure 5: (a) Computational fluid dynamics, (b) geometry, (c) surface mesh, and (d) BuoyantSimpleFoam for the fire stove.

TABle 2: Stove model boundary conditions.

\begin{tabular}{lcc}
\hline Boundary name & Boundary type & Boundary conditions \\
\hline Case wall & Surface & Mild steel $-50 \mathrm{~W} \mathrm{~m}^{-1} \mathrm{~K}^{-1}$ \\
\hline Clay & Wall & $0.25 \mathrm{~W} \mathrm{~m}^{-1} \mathrm{~K}^{-1}$ \\
\hline Sawdust-clay & Wall & $0.06 \mathrm{~W} \mathrm{~m}^{-1} \mathrm{~K}^{-1}$ \\
\hline Sawdust & Wall & $0.08 \mathrm{~W} \mathrm{~m}^{-1} \mathrm{~K}^{-1}$ \\
\hline Cold air inlet & Cold air & $\begin{array}{c}\text { Temperature }=27^{\circ} \mathrm{C} \\
\text { Air velocity }=0.05 \mathrm{~m} \mathrm{~s}^{-1}\end{array}$ \\
\hline Hot air inlet & Hot air & $\begin{array}{c}\text { Temperature }=500^{\circ} \mathrm{C} \\
\text { Air velocity }=0.05 \mathrm{~m} \mathrm{~s}^{-1}\end{array}$ \\
\hline
\end{tabular}

conducted in accordance with Volunteers in Technical Assistance [15, 34]. The parameters measured during stove testing included the mass of fuel used, ambient air temperature, time of starting, time of operation, water temperature, and mass of char produced at the end of testing.

The ambient air temperature was recorded in each experiment using a thermometer with $1^{\circ} \mathrm{C}$ accuracy. The time of starting the fire stove for each fuel was measured using a stopwatch with 1 -second accuracy. This was done to determine the ease with which the fuel starts. The operation time of the fuel in the fire stove was measured using a stopwatch with 1-second accuracy. This was done to simulate the cooking of food using the fire stove prototype. The temperature of the water was recorded after every 2 minutes. The water was allowed to reach boiling point, and the boiling was continued until the 45 minutes of simmering was used up.
2.3.4. Determination of the Insulation Layer Thickness of the Fire Stove. The wall heat flux of the stove was generated. Using the maximum temperature, the minimum thickness of the insulation layer was determined. Given the temperature at the wall and the heat flux, the thickness of the sawdust-clay mixture needed to have an ambient temperature on the outside wall of the insulation layer was determined according to heat conduction law (equation (4)).

$$
Q=\frac{k \times\left(T_{\text {Hot }}-T_{\text {Ambient }}\right)}{L},
$$

where $Q$ is the heat flux ( $\left.\mathrm{W} \mathrm{m} \mathrm{m}^{-2}\right), k$ is the thermal conductivity $\left(\mathrm{W} \mathrm{m}^{-1} \mathrm{~K}^{-1}\right.$ ), $L$ is the thickness of the insulation layer $(\mathrm{cm}), \mathrm{T}_{\text {Hot }}$ is the hot temperature $(\mathrm{K})$, and $\mathrm{T}_{\text {Ambient }}$ is the ambient temperature $(\mathrm{K})$.

2.4. Data Analysis. All numerical data of experiments performed in triplicate were captured in Microsoft Excel 2016 (Microsoft Corporation, USA) and used with the WBT protocol version 4.2.4. The results were subjected to one-way ANOVA followed by Tukey's HSD test with statistical significance set at $P=0.05$. The analyses were performed using $R$ for statistical analysis (R Core Team, 2013).

\section{Results and Discussion}

3.1. Moisture Content of the Biomass Fuels Used. The moisture content (MC) of the biomass fuels is shown in Table 3. The results showed that $S$. spectabilis had the highest 
TABLE 3: Moisture content (\%) of the biomass fuels used.

\begin{tabular}{lcc}
\hline Biomass fuel & Dry basis & Wet basis \\
\hline Eucalyptus grandis & $9.09 \pm 0.08$ & $8.33 \pm 0.06$ \\
Senna spectabilis & $14.29 \pm 0.10$ & $12.50 \pm 0.08$ \\
Pinus caribaea & $11.11 \pm 0.09$ & $10.0 \pm 0.07$ \\
\hline
\end{tabular}

MC, followed by P. caribaea, and lastly E. grandis. Moisture content affects the burning rate of fuels. Dry biomass has a greater heating value (or net energy potential) as it uses little of its energy to evaporate any moisture. Increased moisture means that less energy is available for cooking. Wet or "green" wood does not burn well and wastes most of its heat to produce steam. Worse still, the steam dissolves out flammable and acidic tars which cling to, block, and can very rapidly damage the stove. Almost all problems associated with burning wood are due to the use of damp fuel. To burn effectively, wood needs to be seasoned or dried out to about 15 to $20 \%$ moisture content [35]. According to SOLIFTEC [35], a fresh $1 \mathrm{~kg} \log$ with $60 \%$ moisture may be able to give out just under $2 \mathrm{~kW}$ of heat energy as compared to a $1 \mathrm{~kg}$ dry $\log$ of $25 \% \mathrm{MC}$ which can roughly double the heat per $\mathrm{kW}$ to about $4 \mathrm{~kW}$. Thus, fuels with low MC increase heat energy output. Thus, fuels should be dried to reduce their MC before testing/use. The results of the MC analysis of Eucalyptus wood in this study are comparable to $5.64 \%$ previously reported on a wet basis in Ethiopia [36].

3.2. Calorific Values of Biomass Fuels. The biomass fuels had different heating values with $S$. spectabilis having the highest value of $22.68 \pm 0.075 \mathrm{MJ} \mathrm{kg}^{-1}$ followed by E. grandis with $19.750 \pm 0.050 \mathrm{MJ} \mathrm{kg}^{-1}$ and then $P$. caribaea with $18.684 \pm 0.207 \mathrm{MJ} \mathrm{kg}^{-1}$. The heating value of the fuel used affects the thermal efficiency of stoves as they are directly proportional. The difference is caused by the higher lignin and resin contents in those species. Senna spectabilis could be having more lignin than the rest of the tested wood fuels, hence its high calorific value.

3.3. Time of Starting the Biomass Fuels. The time of starting biomass fuels is related to bulk density. The lower the bulk density of the biomass fuel, the less time of starting and vice versa. Pinus caribaea had the lowest starting time of 0.82 minutes while $E$. grandis had the highest starting time of 2.43 minutes (Figure 6). One-way ANOVA test for the time of starting biomass fuels revealed that there was a significant difference in the time of starting the different biomass fuels $(P=0.0001)$.

3.4. Time to Boil 5 Liters of Water on the Stove. Senna spectabilis had the highest value of boiling time on both cold and hot start of 15 minutes and 12.7 minutes, respectively. Eucalyptus grandis took 10.3 minutes for the cold start and 9.3 minutes for the hot start while $P$. caribaea had the lowest boiling times of 8.2 minutes for the cold start and 7.0 minutes for the hot start (Figure 7). This indicated that more energy was released per unit time with $P$. caribaea when compared to

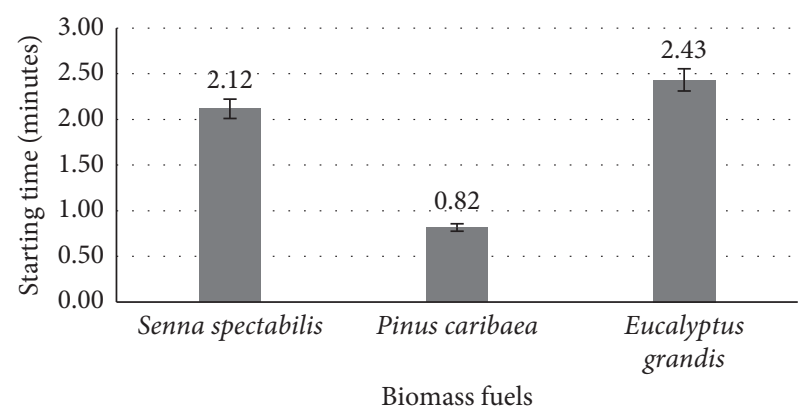

Figure 6: Average time of starting biomass fuels.

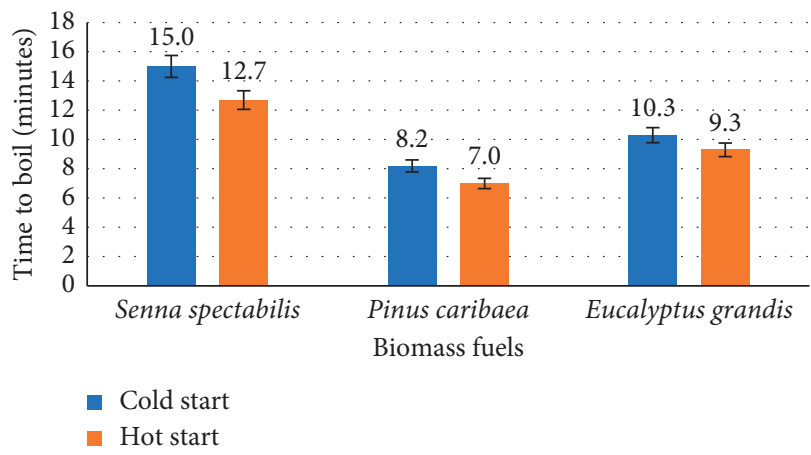

Figure 7: Water boiling test for the biomass fuels used.

S. spectabilis and E. grandis. These differences were significant $(P=0.0008)$ for the hot start test. However, there was no significant difference between pine and Eucalyptus biomass fuels as regards the time taken for the water to boil on the fire stove during the cold start phase $(P=0.1467)$.

According to Ariho et al. [31], biomass fuels with higher energy released per unit time always have a lower boiling time. Therefore, $P$. caribaea which released the most energy per unit time required the lowest energy to boil as compared to S. spectabilis and E. grandis. As depicted in Figure 7, S. spectabilis took the longest time, and this showed that it absorbed less energy per unit time in the fire stove. The lowest time taken to raise $5 \mathrm{~L}$ of water to the boiling temperature by $P$. caribaea could have been due to its structural properties. The structure is widely spread with a large surface area and this allowed it to catch fire and hence bring water to boiling more quickly as compared to the other biomass fuels.

3.5. Burning Rate of the Biomass Fuels. The burning rate of the tested fuels varied as shown in Figure 8. Senna spectabilis had the lowest burning rate of $19 \mathrm{~g} / \mathrm{min}$ on a cold start, followed by $39 \mathrm{~g} / \mathrm{min}$ for E. grandis and P. caribaea with the highest value of $65 \mathrm{~g} / \mathrm{min}$ with similar trends on both hot starts and simmer phase. Bulk density is inversely proportional to the burning rate. Pinus caribaea has a larger surface area, and this explains its high burning rate [31]. One-way ANOVA showed that there were significant differences $(P<0.01)$ in the burning rates of the biomass fuels. According to Ariho et al. [31], the burning rate of fuels is affected by their bulk densities. 


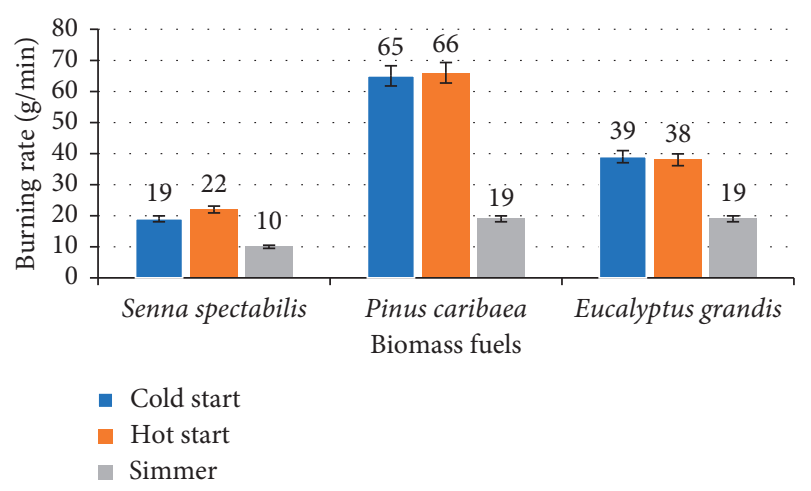

FIGURE 8: Burning rate of the selected biomass fuels on the fire stove prototype.

3.6. Specific Fuel Consumption of the Fire Stove. The specific fuel consumption (SFC) as defined by the WBT protocol is the fuel needed to produce a unit output. It is a measure of the amount of fuel required to produce one liter (or kilogram) of boiling water [7]. The SFC varied for the biomass fuels (Figure 9). Pinus caribaea had the highest SFC of $108 \mathrm{~g} \mathrm{~L}^{-1}$, followed by E. grandis with $82 \mathrm{~g} \mathrm{~L}^{-1}$, and lastly S. spectabilis with the lowest value of $61 \mathrm{~g} \mathrm{~L}^{-1}$. There were significant differences in the SFCs of the biomass fuels when used in the designed stove $(P<0.01)$. It is reported that SFC is inversely proportional to the bulk density of the biomass fuel [31]; i.e., the higher the bulk density of the biomass fuel, the lower the SFC and vice versa. Lower SFC leads to a cleaner and faster cooking [31]. In Figure 9, the sharp increase in SFC of P. caribaea could be due to its low density as compared to the rest of the tested fuels and this contributed to its high amount of fuel weight consumed per liter of water boiled.

3.7. Thermal Efficiency of the Fire Stove. The WBT is a simplified simulation of a typical cooking process that measures how efficiently a stove utilizes fuel to heat water in a cooking pot and the quantity of emissions produced thereof [37]. The WBT entails three sequential phases: cold start high power phase, hot start high power phase, and the simmer phase. Measurement of the stove's performance at both high and low (simmer phase) powers simulates what is likely to occur when cooking foods that involve boiling and simmering. This cooking type is the commonest [38]. The thermal efficiency of the fire stove obtained using the tested biofuels is shown in Table 4. Senna spectabilis had the highest thermal efficiency of $35.5 \%$ on cold start while P. caribaea had the lowest thermal efficiency of $19.3 \%$ on cold start. Senna spectabilis had the lowest thermal efficiency of $23.8 \%$ on simmer. The differences in the thermal efficiencies were statistically significant $(P<0.001)$. Energy efficiency has an effect on the performance of the biomass fuels in the fire stove during boiling. Bulk density of the fuels influenced their burning rates with more dense fuels having lower burning rates than their less dense counterparts.

Schreiner [39] reported that the thermal efficiency of shielded fire stoves with low insulations tested using pine

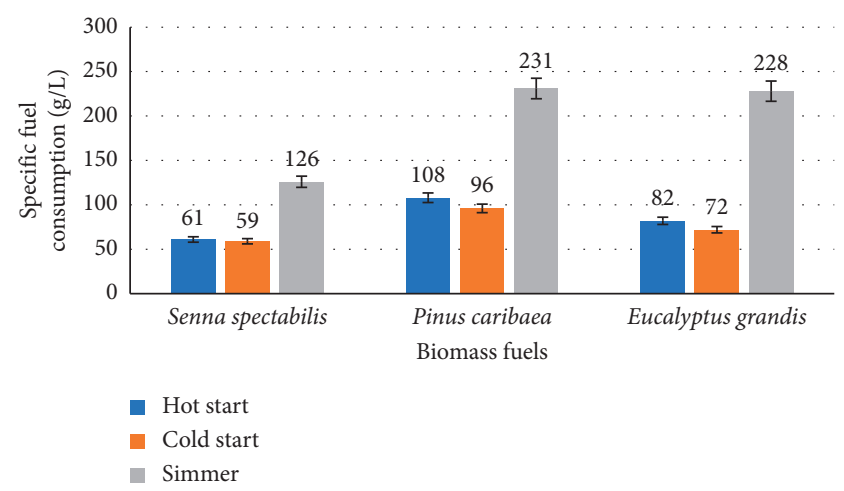

FIgURE 9: The specific fuel consumption of the tested biomass fuels.

TABle 4: Thermal efficiency (\%) of the fire stove using the selected biomass fuels.

\begin{tabular}{lccc}
\hline Biomass fuel & Cold start & Hot start & Simmer \\
\hline Senna spectabilis & $35.5 \pm 2.5$ & $35.0 \pm 2.6$ & $23.8 \pm 1.2$ \\
Pinus caribaea & $19.3 \pm 1.2$ & $22.0 \pm 1.0$ & $34.3 \pm 1.5$ \\
Eucalyptus grandis & $25.7 \pm 1.7$ & $29.0 \pm 2.0$ & $29.7 \pm 1.5$ \\
\hline
\end{tabular}

species was $13 \%, 18 \%$, and $21 \%$ on a cold start, hot start, and simmer phases, respectively. The values were comparatively lower than the ones obtained using P. caribaea in this study. This, therefore, implies that insulating the stove with sawdust increased its thermal efficiency.

3.8. CFD Modelling Results. Computational fluid dynamics modeling was done to visualize the combustion processes within the chamber and also to show the temperature contours across the wall of the stove. This helped in observing the effect of insulations on the stove during operation.

3.8.1. Temperature Contours. The temperature contours of the fire stove generated are shown in Figure 10. Areas of warm and hot temperatures are depicted by orange and red colors, while cold temperatures are shaded blue and purple. The stove remained cold, so the hot air was restricted to the combustion chamber, thereby increasing the heat transfer efficiency to the cooking pot.

3.8.2. Monitor Plots. The plots stabilized after 250 seconds. The temperature and velocity profiles are shown in Figures 11 and 12, respectively. The temperature and velocity fields of the stove were generated (Figures 13 and 14, respectively). The model showed that the temperature can be around $600 \mathrm{~K}$ inside whereas the wall temperature can rise up to $800 \mathrm{~K}$ and continues decreasing on the outside wall of the stove. This means that the clay-sawdust layer provided good thermal insulation of the fire stove due to a drop in temperature toward the outer wall.

As shown in Figure 11, the temperature inside the combustion chamber increased with time and then remained constant at a maximum temperature of $900 \mathrm{~K}$. The 


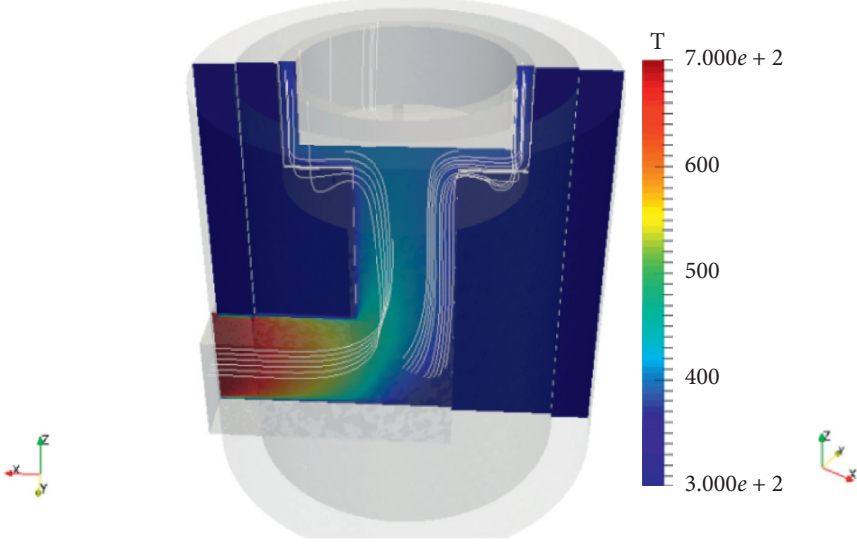

(a)

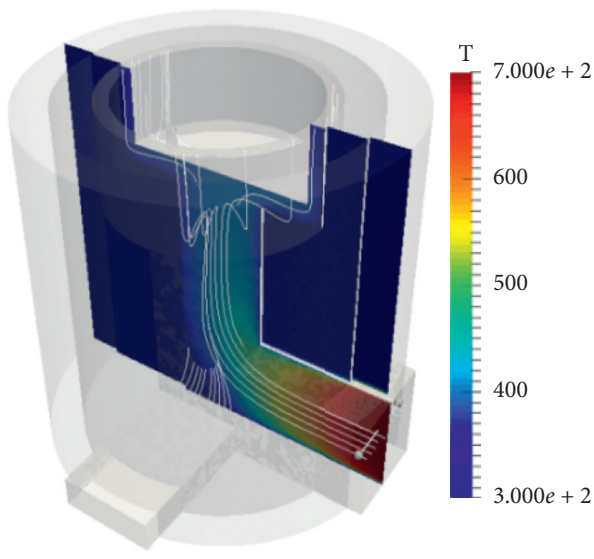

(b)

FIGURE 10: Temperature contours for stove with insulations of (a) clay-sawdust and (b) sawdust alone.

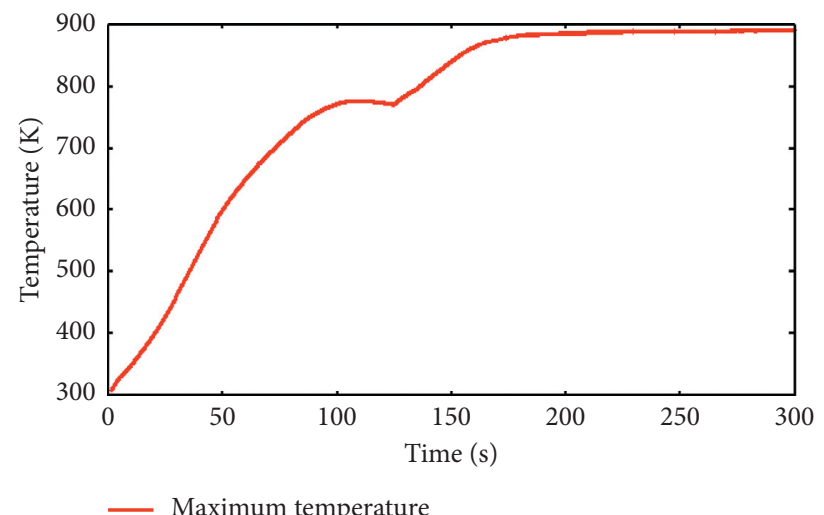

Figure 11: Temperature profile inside the combustion chamber.

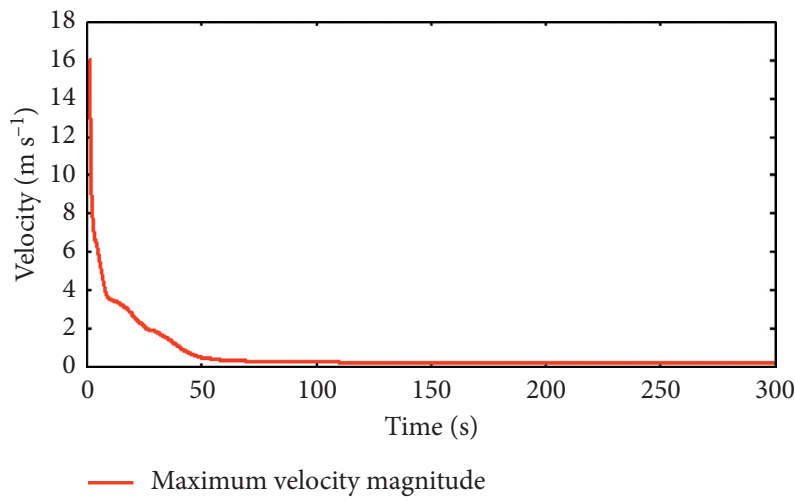

FIGURE 12: Velocity profile inside the combustion chamber.

temperature inside the combustion chamber of the stove can be maintained, and hence, heat can be transferred to the cooking pot.

The velocity inside the combustion chamber decreased rapidly and remained constant (Figure 12). This means that the flow of hot gases within the chamber was not affected by the outside environment as it was controlled within the chamber.

As depicted in Figure 13, temperature fields inside the combustion chamber were $600 \mathrm{~K}$ with red-orange color dominating inside the chamber up to the top which showed the effect of high temperatures. The flue gases were spread evenly within the chamber and hence good cooking performance could be achieved. The rise in temperature at the wall up to $800 \mathrm{~K}$ was due to cast iron material which is a good thermal conductor.

In Figure 14, the flow velocity was the highest at the air inlet and reduced within the combustion chamber with an almost constant flow since it was colored green almost 

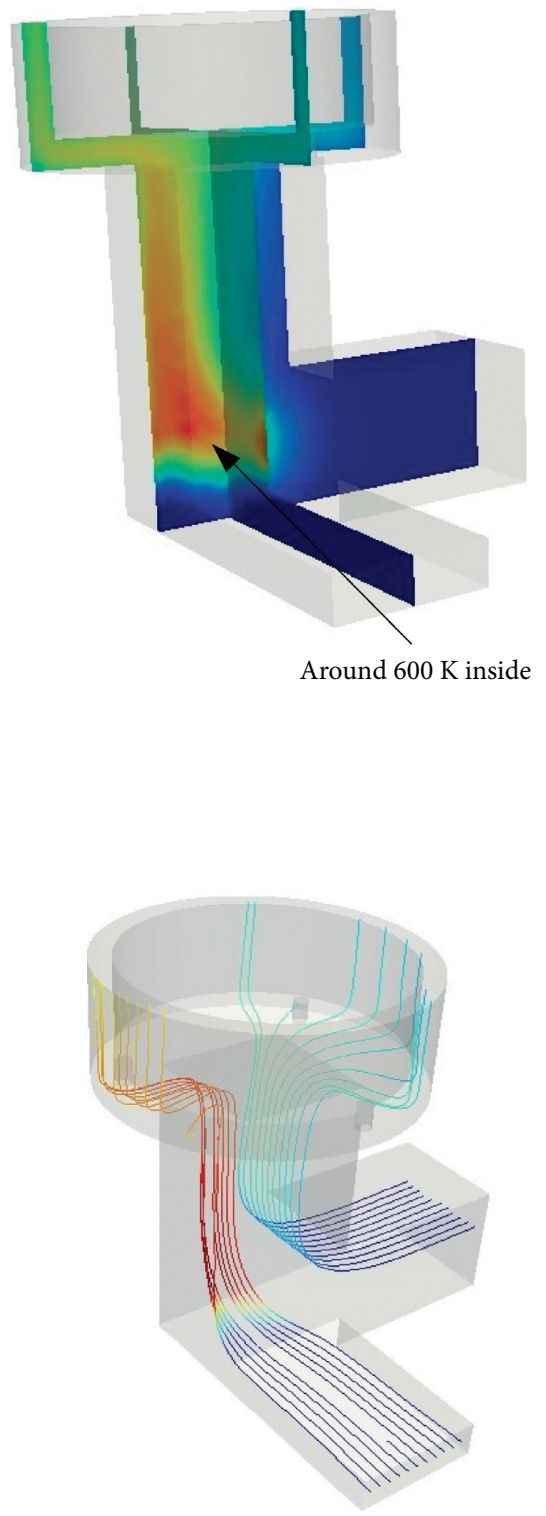

(a)
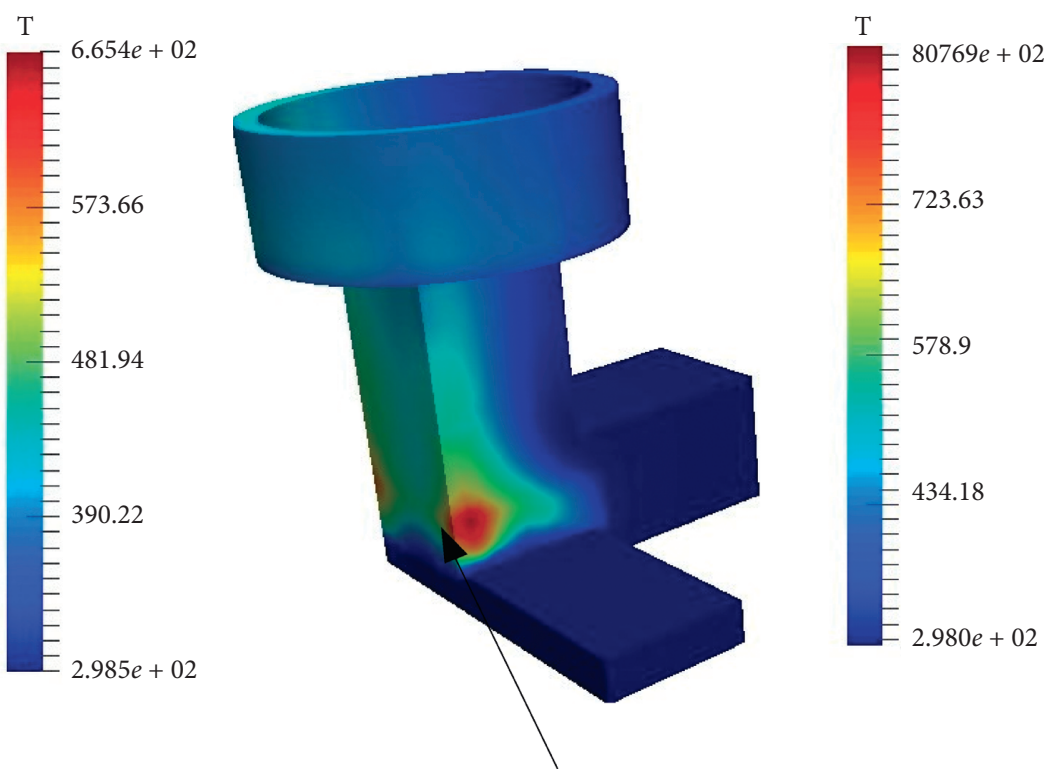

FIgURE 13: Temperature fields.
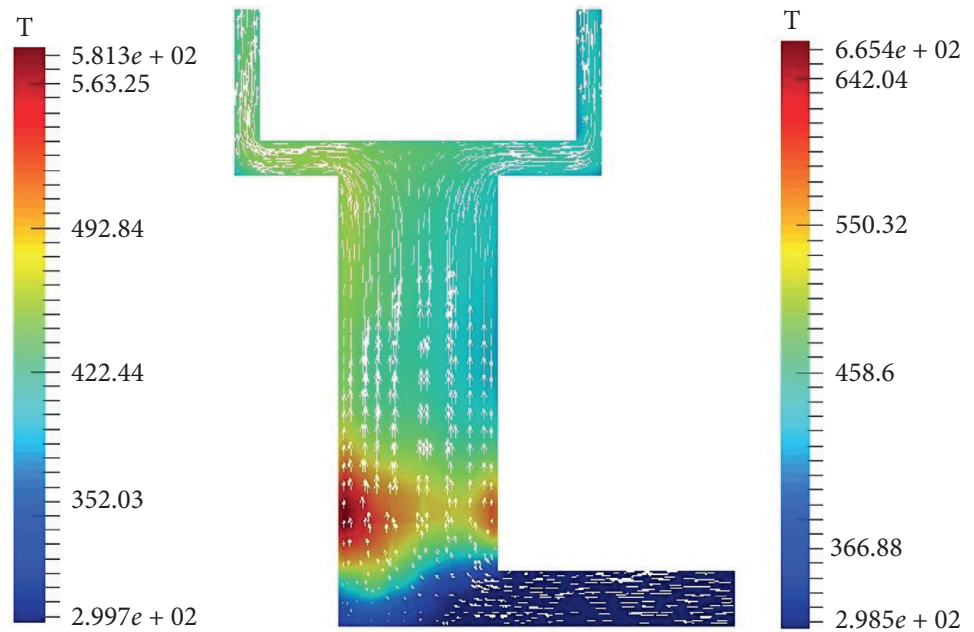

(b)

FIgURE 14: Velocity fields: (a) streamlines of velocity colored by temperature and (b) contour of temperature with velocity vectors.

throughout. This was due to the shielding of the combustion chamber of the insulated fire stove that reduces flow velocity as compared to traditional open stoves. The flow velocity was the lowest at the fire inlet where combustion temperature was the highest.

3.9. Minimum Thickness of Insulation Layer. The heat flux generated is shown in Figure 15. The negative value means that the heat flux was leaving the fluid domain. The minimum value was $-540 \mathrm{~W} \mathrm{~m}^{-2}$ while the maximum value obtained was $10.27 \mathrm{~W} \mathrm{~m}^{-2}$. The heat flux was distributed throughout the combustion chamber. Given thermal conductivity, $k=0.06 \mathrm{~W} \mathrm{~m}^{-1} \mathrm{~K}^{-1}$ for $30 \%$ sawdust in clay, taking $Q=600 \mathrm{~W} \mathrm{~m}^{-2}$ to be conservative, the minimum thickness of the insulation layer was $6 \mathrm{~cm}$ (computed by substitution in equation (4)). Therefore, a thickness layer less than $6 \mathrm{~cm}$ ensured good insulation of the stove. The insulation layer thickness could be reduced to $6 \mathrm{~cm}$ while the heat remains restricted to the combustion chamber. This, therefore, can give a reduction in the weight of the stove and thus makes it more portable. According to Folaranmi [30], insulation 


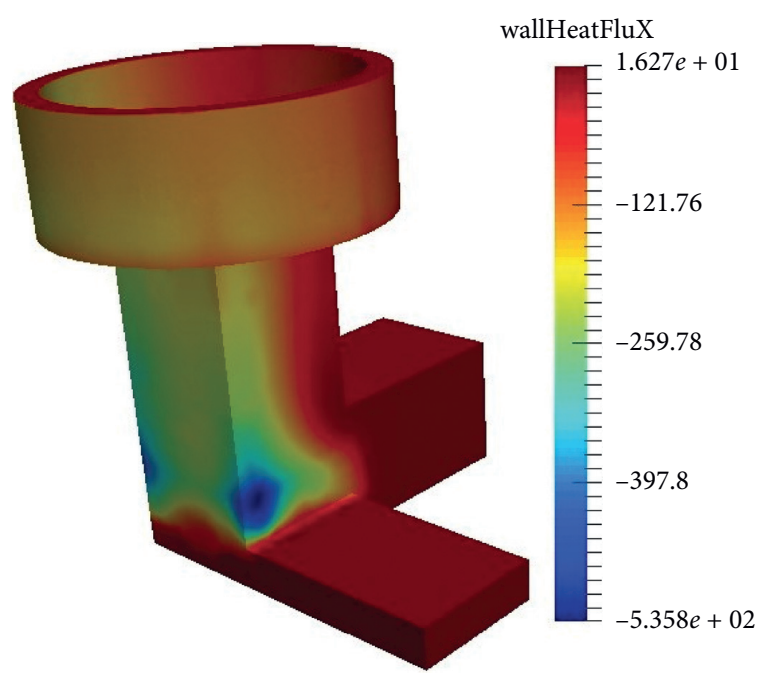

Figure 15: Wall heat flux of fire stove.

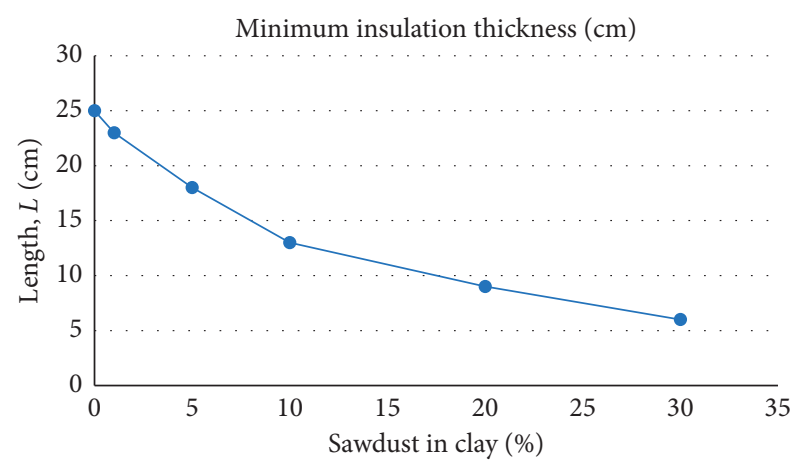

FIGURE 16: Influence of sawdust on the thickness of the insulation.

thickness can be reduced by having more sawdust since increasing the sawdust percentage reduces the thermal conductivity (Figure 16). With more sawdust, therefore, the thickness could even be below $6 \mathrm{~cm}$.

\section{Conclusion}

The construction and testing of an insulated fire stove prototype of a $26 \mathrm{~cm}$ saucepan diameter were done, and the stove was investigated with computational fluid dynamics software. A water boiling test was conducted to measure the overall performance of a cooking stove using the three biomass fuels, namely, S. spectabilis, $P$. caribaea, and E. grandis. Senna spectabilis had the highest thermal efficiency of $35.5 \%$ while E. grandis and Pinus caribaea had average thermal efficiencies of $25.7 \%$ and $19.3 \%$ on cold start. Computational fluid dynamics indicated that heat was concentrated on the inside of the combustion chamber due to perfect insulation of the stove with sawdust as temperatures decreased toward the wall of the stove. The heat flux generated indicated that the thickness insulation layer of the stove can be $6 \mathrm{~cm}$ or less while the stove would still remain hot.

\section{Data Availability}

The raw data supporting the conclusions of this study are available from the corresponding author upon reasonable request.

\section{Conflicts of Interest}

The authors declare that there are no conflicts of interest regarding the publication of this paper.

\section{Acknowledgments}

The authors thank the manager, Biomass Energy Resource and Training Centre (BERTC)-Nyabyeya Forestry College, Masindi, Uganda, for availing the laboratory and testing apparatus that made this research a success. Jasper Okino and Elly Olomo are grateful to the Mobility for Innovative Renewable Energy Technologies (MIRET) scheme (under the Intra-Africa Academic Mobility Scheme of the European Union Funding) hosted at Moi University for the scholarships awarded to them that made this collaboration possible. Timothy Omara is grateful to the World Bank and the InterUniversity Council of East Africa (IUCEA) for the scholarship awarded to him through the Africa Center of Excellence II in Phytochemicals, Textiles, and Renewable Energy (ACE II PTRE) at Moi University (Kenya) which made this collaboration possible.

\section{References}

[1] B. J. Das, S. Das, R. N. Boro, P. B. Bishal, and K. Ashim, "Study and fabrication on heat efficient stove of low smoke emission," Journal of The Institution of Engineers (India), Series E, 2021.

[2] G. Sime, G. Tilahun, and M. Kebede, "Assessment of biomass energy use pattern and biogas technology domestication programme in Ethiopia," African Journal of Science, Technology, Innovation and Development, vol. 12 , no. 6, pp. $747-$ 757, 2020.

[3] R. Quansah, S. Semple, C. A. Ochieng et al., "Effectiveness of interventions to reduce household air pollution and/or improve health in homes using solid fuel in low-and-middle income countries: a systematic review and meta-analysis," Environment International, vol. 103, pp. 73-90, 2017.

[4] J. Nyika, A. A. Adediran, A. A. Olayanju, S. E. Olanrewaju, and F. Odikpo, "The potential of biomass in Africa and the debate on its carbon neutrality," in Biomass, pp. 1-19, IntechOpen, London, UK, 2020.

[5] E. Getahun, D. Tessema, and N. Gabbiye, "Design and development of household gasifier cooking stoves: natural versus forced draft," in Advances of Science and Technology. ICAST 2018, F. Zimale, T. Enku Nigussie, and S. Fanta, Eds., Vol. 274, Springer, Cham, Switzerland, 2019.

[6] A. K. Quinn, N. Bruce, P. Elisa et al., "An analysis of efforts to scale up clean household energy for cooking around the world," Energy for Sustainable Development, vol. 46, pp. 1-10, 2018.

[7] A. Shanono, I. Diso, and I. Garba, "Performance and emission characteristics of liquid biofuels cooking stoves," Athens Journal of Technology \& Engineering, vol. 7, no. 3, pp. 219238, 2020. 
[8] V. Tidze, M. Ibrahim, and T. Issac, "Dynamics of household energy and cooking stoves in maroua, far north region of Cameroon," Journal of Scientific Research and Reports, vol. 9, no. 4, pp. 1-13, 2016.

[9] M. Rasoulkhani, M. Ebrahimi-Nik, M. H. Abbaspour-Fard, and A. Rohani, "Comparative evaluation of the performance of an improved biomass cook stove and the traditional stoves of Iran," Sustainable Environment Research, vol. 28, no. 6, pp. 438-443, 2018.

[10] C. Samal, P. C. Mishra, S. Mukherjee, and D. Das, "Evolution of high performance and low emission biomass cookstoves-an overview," AIP Conference Proceedings, vol. 2200, p. 220021, 2019.

[11] WHO, "Improving the health impacts of airports," Bulletin of the World Health Organization, vol. 96, pp. 518-519, 2018.

[12] K. D. Adem, D. A. Ambie, M. P. Arnavat et al., "First injera baking biomass gasifier stove to reduce indoor air pollution, and fuel use," AIMS Energy, vol. 7, no. 2, pp. 227-245, 2019.

[13] D. Bamwesigye, P. Kupec, G. Chekuimo et al., "Charcoal and wood biomass utilization in Uganda: the socioeconomic and environmental dynamics and implications," Sustainability, vol. 12 , no. 20 , p. $8337,2020$.

[14] P. Mugabi and D. B. Kisakye, "Status of production, distribution and determinants of biomass briquette acceptability in Kampala city, Uganda," Maderas. Ciencia y tecnología, vol. 23, no. 13, pp. 1-8, 2021.

[15] A. A. Bantu, G. Nuwagaba, S. Kizza, and Y. K. Turinayo, "Design of an improved cooking stove using high density heated rocks and heat retaining techniques," Journal of Renewable Energy, vol. 2018, Article ID 9620103, 9 pages, 2018.

[16] R. Janssen and D. Rutz, Bioenergy for Sustainable Development in Africa, Springer Science for Business Media B.V., 2012.

[17] S. C. Bhattacharya and P. Abdul Salam, A review of selected biomass energy technologies: gasification, combustion, carbonization and densification, Asian Regional Research Programme in Energy, Environment and Climate (ARRPEEC), Pathumthani, Thailand, 2006.

[18] Ministry Of Energy And Mineral Development (MEMD), Construction Manual for Household Rocket Stoves, Republic of Uganda, Ministry of Energy and Mineral Development, Kampala, Uganda, 2008.

[19] O. J. Oyejide, M. O. Okwu, and L. K. Tartibu, "Adaptive design and development of a modular water hyacinth briquette stove," Energy Sources, Part A: Recovery, Utilization, and Environmental Effects, pp. 1-19, 2019.

[20] H. B. Darlami, B. B. Ale, and G. R. Pokharel, "Experimental analysis of thermal efficiency of mud improved cookstove with variation of different parameters and economic analysis," Journal of the Institute of Engineering, vol. 15, no. 3, pp. 385-392, 2019.

[21] H. E. Pérez, I. O. Mulumba, S. D. Alfonso Solar, M. M. C. Gómez, and P. Bastida-Molina, "Sustainable cooking based on a $3 \mathrm{~kW}$ air-forced multifuel gasification stove using alternative fuels obtained from agricultural wastes," Sustainability, vol. 12, no. 18, p. 7723, 2020.

[22] P. Comsawang, S. Nanetoe, and N. Soponpongpipat, "CoFiring of sawdust and liquid petroleum gas in the application of a modified rocket stove," Processes, vol. 8112 pages, 2020.

[23] M. Njenga, J. K. Gitau, M. Iiyama, R. Jamnadassa, Y. Mahmoud, and N. Karanja, "Innovative biomass cooking approaches for sub-Saharan Africa," African Journal of Food, Agriculture, Nutrition and Development, vol. 19, no. 01, pp. 14066-14087, 2019.

[24] I. J. Bhanap and R. D. Deshmukh, "Development of an improved sawdust gasifier stove for industrial applications,"
Journal of Renewable and Sustainable Energy, vol. 4, Article ID 063113, 2012.

[25] B. O. Bolaji, "The use of sawdust as an alternative source of energy for domestic cooking and as A means of reducing deforestation," Global Journal of Environmental Sciences, vol. 4, no. 1, pp. 73-76, 2005.

[26] O. Y. Ogunsanwo, "Effective management of wood wastes for sustainable woodutilization in Nigeria," in Proceedings of the 27th Annual Conference of Forestry Association of Nigeria Abuja, L. Popoola, J. E. Abu, and P. I. Oni, Eds., pp. 226-234pp. 226-, Abuja, Nigeria, September 2001.

[27] J. J. Owonubi and S. O. O. Badejo, "Industrial Scale Wood Waste Conversion into Building Materials at FRIN, Ibadan," in Proceedings of the 38th Annual Conference of Science Association of Nigeria, Ekpoma, Nigeria, December 2000.

[28] M. Njenga, N. Karanja, R. Jamnadass, J. Kithinji, C. Sundberg, and R. Jirjis, "Quality of briquettes produced locally from charcoal dust and sawdust in Kenya," Journal of Biobased Materials, vol. 7, no. 3, pp. 315-322, 2013.

[29] Ministry Of Energy And Mineral Development (MEMD), How to Build the Improved Household Stoves, Energy Advisory Project, 2004, https://www2.ic.edu/klein/Econ\%20344/fire\% 20stoves/House_Hold_Stove_Manual.pdf.

[30] J. Folaranmi, "Effect of sawdust additive on the properties of clay," AU Journal of Technology, vol. 13, no. 1, pp. 53-56, 2009.

[31] D. Ariho, P. Tumutegyereize, and K. Bechtel, Evaluation of the Energy Efficiencies of Commonly Available Biomass Fuels in Uganda in a Champion-2008, http://www.bioenergylists.org/ files/BIOMASS\%20FUELS\%20IN\%20A\%20TLUD\% 20GASIFIER\%20STOVE.pdf, 2010.

[32] J. M. Kirima and T. Omara, "Chemical composition and insecticidal activity of Pinus caribaea Morelet var. hondurensis needles against Sitophilus zeamais Motschulsky and Callosobruchus maculatus Fabricius," in Proceedings of the International Conference on Phytochemistry, Textiles \& Renewable Energy for Sustainable Development, Moi University, Eldoret, Kenya, August 2020.

[33] W. R. Odogola and R. Henriksson, "Post harvest management and storage of maize," in Technical Systems for Agriculture, UNDP/OPS Regional Programme on Agricultural Operations Technology for Small Holders in East and Southern Africa, pp. 27-48, 1991.

[34] Volunteers in Technical Assistance, Testing the Efficiency of Wood-burning Cookstoves: Provisional International Standards, The Partnership for Clean Indoor Air, 1985.

[35] Solid Fuel Technology Institute (SOLIFTEC), Moisture Content of Wood Fuel, Britain and Ireland, http://www. soliftec.com/woodfuel.htm, 2014.

[36] K. D. Adem and D. A. Ambie, "Performance and emission reduction potential of micro-gasifier improved through better design," AIMS Energy, vol. 5, no. 1, pp. 63-76, 2017.

[37] GACC, The Water Boiling Test Version 4.2.3: Cook Stove Emissions and Efficiency in a Controlled Laboratory Setting, https://www.cleancookingalliance.org/binary-data/ DOCUMENT/file/000/000/399-1.pdf, 2014.

[38] N. MacCarty, D. Still, and D. Ogle, "Fuel use and emissions performance of fifty cooking stoves in the laboratory and related benchmarks of performance," Energy for Sustainable Development, vol. 14, no. 3, pp. 161-171, 2010.

[39] N. H. Schreiner, "Performance characteristics and design recommendations for biomass burning stoves using earthen construction materials," Masters Thesis, Michigan Technological University, 2011. 